\title{
A comunicação e a condição pública dos processos de mobilização social ${ }^{1}$
}

\author{
Márcio Simeone HENRIQUES ${ }^{2}$
}

\section{RESUMO}

Em sociedades democráticas contemporâneas, o termo mobilização social tem sofrido um reposicionamento semântico para designar processos inseridos na vida cotidiana. Isso se dá consoante com as prerrogativas de proposição e discussão de temas publicamente relevantes e com as demandas de participação cívica nos negócios públicos. Dois fatores mutuamente condicionantes - a visibilidade e a constituição de públicos - são essenciais para explicar as condições sob as quais se forma o caráter público dos processos mobilizadores. Tomada a constituição dos públicos a partir de quatro aspectos - afetação, controvérsia, virtualidade e performance - evidencia-se que a condição pública dos processos de mobilização social está associada à comunicação e às interações na vida ordinária e, por isso, precisa ser constante e cotidianamente gerada.

Palavras-chave: comunicação, mobilização social, cidadania, públicos

\begin{abstract}
In contemporary democratic societies, the term social mobilization has been a semantic replacement in order to describe processes embedded in everyday life. It is consonant with the prerogatives of public discussion and with demands of civic participation in public affairs. Two mutually conditioning factors - visibility and the constitution of publics - are essential to explain the conditions under which the public character of mobilizing processes is formed. Taking the constitution of the publics from four aspects - affectation, controversy, virtuality and performance - become evident that the public

\footnotetext{
${ }^{1}$ Trabalho apresentado à terceira edição da Revista Ação Midiática - Estudos em Comunicação, Sociedade e Cultura, publicação ligada ao Programa de Pós-Graduação em Comunicação e Sociedade, da Universidade Federal do Paraná.

${ }^{2}$ Professor do Departamento de Comunicação Social da Universidade Federal de Minas Gerais. Doutor em Comunicação Social pela UFMG. E-mail: simeone@fafich.ufmg.br
} 
condition of social mobilization processes is tied to communication and interactions in ordinary life and, therefore, must be generated daily.

Keywords: communication, social mobilization, citizenship, publics

O termo mobilização social tem-se tornado cada vez mais corrente no Brasil para designar uma prática de movimentação de pessoas e instituições, essencial para o exercício da cidadania num contexto democrático. Correspondendo ao alargamento dessas práticas, em virtude de uma cidadania ampliada e de um modelo de democracia participativa, esse termo também passou nos últimos anos por um reposicionamento semântico, especialmente no que se refere ao seu estatuto acadêmico, em que a atenção ao processo político trazia consigo o foco no confronto social. Sob aquela perspectiva, o levantamento de "multidões de descontentes" e a provocação de distúrbios e a subversão da ordem pública como desencadeadores de movimentos e de revoluções geraram uma preocupação em compreender a dinâmica de recrutamento dos ativistas e, sobretudo, as escolhas racionais dos diversos atores, em termos de oportunidades e restrições para essa movimentação (TILLY, 1978; TILLY; TARROW; McADAM, 2009).

Para Tilly (1978, p. 7), a mobilização é vista como um componente essencial da ação coletiva, definida como um "processo pelo qual um grupo adquire controle coletivo sobre os recursos necessários para a ação". Esses recursos podem ser tanto bens quanto armas ou a própria força de trabalho, que são arregimentados e postos em ação por interesses compartilhados. E esses interesses são medidos pelos ganhos e perdas que resultam da interação de grupos com outros grupos. Essa abordagem confere grande atenção às formas organizativas de mobilização social, sejam as mais pontuais e efêmeras, como os eventos de protesto, sejam as mais institucionalizadas, como as associações criadas em função de determinadas causas (organizações de protesto) ou ainda as mais fluidas e difusas - os movimentos, tomados como formas de opinião de massa (TARROW, 2011). Nesse último caso, McCarthy e Zald (1977, p. 153) veem os movimentos como "conjunto de opiniões e crenças que representam as preferências de uma população para mudança de alguns elementos da estrutura social ou da distribuição de recompensas (ou ambos)". O próprio Tilly (1998, p. 467) define um movimento 
social como uma espécie de campanha, um fenômeno de opinião de massa lesada, mobilizada contra as autoridades que "demanda a correção de um mal, na maioria das vezes um problema sofrido por uma população bem especificada".

A preocupação com os recursos, com as características dos atores, com as formas organizativas, com as oportunidades políticas de ação e com as consequências práticas da mobilização coletiva para a efetiva transformação social não esgotam, porém, as possibilidades de explicar as várias dimensões implicadas nesse processo. Não obstante aquelas abordagens fazerem referência ao conjunto de opiniões e crenças, pouca atenção lançam sobre aspectos importantes que ajudam a compreender a dinâmica mobilizadora e que passaram a ser objeto de outros tipos de abordagens recentes. Dentre vários desses aspectos, podemos aqui destacar pelo menos dois: a formação das opiniões coletivas e a manifestação pública dessas estruturas de preferências. Esses elementos passaram a ser considerados, por exemplo, por estudos da psicologia social e da ciência política acerca dos movimentos sociais, a partir das próprias mudanças de forma no exercício político e da emergência de novos sujeitos sociais coletivos. Além disso, tais elementos nos interessam de perto, pois tornam manifesta uma contribuição potencial específica dos estudos de comunicação e, sob um foco particular, de relações públicas.

\section{0 sentido ordinário da mobilização social}

Em outro trabalho, observamos essas transformações como um ponto de inflexão na prática mobilizadora, especialmente nas modalidades de ativismo, que decorre da incorporação de novos contingentes até então excluídos da participação na vida política e nos negócios públicos, dos arranjos pluralísticos e policêntricos que emergem nos cenários urbanos (e que mobilizam parcelas mais significativas da população em torno de questões cotidianas) e das novas formas de aliança acarretadas pela mul tiplicidade de formas associativas, que geram uma atuação em redes (HENRIQUES, 2007). Laclau apontava, já na década de 1980, uma pluralização dos espaços políticos, já que as mobilizações populares não mais estariam baseadas "num modelo de sociedade total ou na cristalização, em termos de equivalência de um único conflito que divida a totalidade do social em dois campos, mas numa pluralidade de exigências concretas" (LACLAU, 
1985, p. 41). A ação coletiva sob formas difusas e reticulares, composta por fenômenos fragmentados e heterogêneos, não escapa à observação de Melucci, que a associa à inadequação da visão de certa unidade exterior para descrever a realidade e a dinâmica dos movimentos: "os movimentos contemporâneos assumem a forma de redes de solidariedade. (...) São sistemas de ação, redes complexas entre diferentes níveis e significados da ação social” (MELUCCI, 1996, p. 4). Nesta direção, Hardt e Negri (2005, p. 118) observam que a mobilização e a luta sob esta nova configuração (reticular) não recorrem estritamente à disciplina, mas aos valores de abertura, criatividade, comunicação e cooperação auto-organizada, o que pressupõe a "construção de novos circuitos de comunicação, novas formas de colaboração social e novos modos de interação". Essas ideias comportam desafios para a compreensão dos processos mobilizadores pelas lentes da comunicação, como os de compreender quais são as novas modalidades de interação postas em prática, quais as lógicas e as dinâmicas desses circuitos comunicativos, como se constroem por meio de tais circuitos os significados da ação social e quais são os sentidos que, coletivamente gerados e afirmados, sustentam publicamente a própria ação.

O termo mobilização social não apenas adquire novos (e variados) significados, como também se expande sobremaneira a sua aplicação. Como prática, deixa de ter um caráter extraordinário, para assumir um sentido ordinário - já que corresponde às muitas formas de movimentação que objetivam transformações sociais, inseridas no correr da vida comum do dia a dia, o que se complementa com um quadro de inovação institucional. Analisando as sociedades complexas contemporâneas, Melucci aponta que, em sua observação, "as novas formas de agregação social têm uma natureza permanente e não-conjuntural" e que a movimentação se dá hoje por meio de "uma rede de pequenos grupos imersos na vida cotidiana que requerem um envolvimento pessoal na experimentação e na prática da inovação cultural" (MELUCCI, 1989, p. 50, 61). Bernardo Toro (1996, p. 34) também faz essa remissão ao cotidiano, ao enfatizar que a mobilização "não significa levar uma multidão às ruas". Para o autor, ela se dá quando 
"todo um conjunto de reeditores ${ }^{3}$, em seu cotidiano, está tomando decisões, desenvolvendo discursos e atuando em função de um imaginário".

Essa trivialização dá uma amplitude para a ação coletiva capaz de abarcar diversos níveis de formação e de organização que não se restringem aos movimentos em massa ou a projetos de ação política específicos como a militância partidária. Já constatamos que esse uso se estendeu rapidamente a todo tipo de processo participativo, sejam os processos próprios e autônomos da sociedade civil, sejam projetos de gestão pública democrática que demandam participação cívica na administração dos negócios públicos e, ainda além, em processos cooperativos autogestionados (HENRIQUES, 2010). Assim, sejam quais forem as motivações específicas, os processos de mobilização são vistos como requisitos para a prática democrática, que demanda participação ativa dos sujeitos e engajamento cívico.

De fato, o reposicionamento conceitual implica em dificuldades para delimitar e até mesmo classificar os variados tipos de mobilização que uma sociedade é capaz de encetar. É mais fácil observar as evidências dessa mobilização quando ela se torna uma mani festação pública com alguma repercussão. Daí porque a ideia de mobilização social fica, de todo modo, presa à expressão evidente do ato mobilizador. Numa escala maior, porém, o processo mobilizador não pode ser explicado apenas por sua face visível. Melucci (1989, p. 61) nos fornece uma importante pista ao observar que os movimentos sociais contemporâneos possuem uma dinâmica que alterna momentos de latência e de visibilidade, o que chama de "modelo bipolar". Enquanto a latência tem uma função de permitir aos sujeitos criar novos códigos culturais e experimentá-los em grupo, o momento da visibilidade - da mobilização pública - "indica ao resto da sociedade que o problema específico está ligado à lógica geral do sistema e também que modelos culturais alternativos são possíveis".

O que aqui nos interessa, no entanto, é mostrar algumas evidências de que a comunicação é, sob este ponto de vista, um elemento-chave para a compreensão dos processos mobilizadores. Podemos considerar que o entendimento dos processos comunicacionais implicados se dá pelo menos em duas direções. A primeira tem a ver com o conjunto de interações entre os sujeitos que se mobilizam e a segunda com as

\footnotetext{
${ }^{3} \mathrm{O}$ autor chama de reeditores todas as pessoas que possuem um público próprio sobre o qual têm influência (não necessariamente lideranças formais). É uma "pessoa que pode negar, transformar, introduzir ou criar sentidos frente ao seu público" (TORO, 1996, p. 32).
} 
estratégias de visibilidade que buscam tanto posicionar o grupo mobilizado e a questão que ele defende quanto conquistar o envolvimento de outros públicos em seu favor. Quanto à primeira, Bernardo Toro já nos chamava à atenção para o compartilhamento de visões, informações e discursos entre os sujeitos como requisitos para um processo de mobilização social, por meio de ações de comunicação (TORO; WERNECK, 2004). Tomada em sentido amplo, a comunicação aqui é responsável pela manutenção de estruturas mobilizadoras horizontais, isto é, pela criação das condições de ação em rede e de coesão entre os atores mobilizados. Já quanto à segunda, entra em jogo a visibilidade da causa, do movimento e de seu posicionamento perante todo um conjunto de públicos. Ambas as direções que apontamos remetem a uma questão crucial que é a condição pública sob a qual os processos de mobilização social têm que se desenvolver. Pretendemos aqui levantar alguns pontos para melhor compreensão acerca da formação dessa condição, discutindo o modo como se dá comunicativamente no curso das interações da vida cotidiana.

\section{$2 \mathrm{O}$ duplo condicionamento do caráter público}

Aspectos importantes para explicar essa condição pública podem ser explorados a partir de nossa definição de mobilização social como sendo a "reunião de sujeitos que definem objetivos e compartilham sentimentos, conhecimentos e responsabilidades para a transformação de uma dada realidade, movidos por um acordo em relação a determinada causa de interesse público" (HENRIQUES et al., 2004). Com essa definição, indicamos principalmente a ligação entre os processos de mobilização e de formação do interesse público. Se a primeira parte dessa definição traça o caráter coletivo da mobilização - ou seja, da condição de formação de um grupo mobilizado - é a segunda parte que nos remete, em suma, ao seu caráter público. Então, sob quais condições se atribui um caráter público ao processo de mobilização?

O que chamamos de condição pública refere-se pelo menos a dois fatores mutuamente condicionantes que presidem a formação de uma causa dirigida ao interesse público. O primeiro, obviamente, é o da visibilidade. É um fator percebido e demandado de forma clara e imediata por qualquer grupo mobilizado, mesmo que por mera intuição. Pode ser entendida como um recurso essencial para que os sujeitos 
possam se engajar em discussões públicas, propor questões e posicionar seus interesses quanto aos temas debatidos ${ }^{4}$. A necessidade de propagar suas ideias, de divulgar sua causa, de preparar seus argumentos para inserir-se nos debates correntes ou mesmo para iniciar discussões ausentes da esfera pública induz a que estes grupos busquem estrategicamente alguma forma de visibilidade. Entretanto, o que desejamos observar é que, embora seja em si mesmo um elemento forte, a visibilidade não é suficiente para gerar toda a condição pública de um processo de mobilização social, já que ela mesma está sujeita a outro condicionante, qual seja, a formação de públicos (e, por extensão, do interesse público). É necessário que uma questão, inicialmente percebida em âmbitos privados, ganhe ampla visibilidade para os públicos e, com isso, possa ser discutida como al go que (mesmo que de modo presumido) leva em conta o interesse de todos.

Com isso, a situação de visibilidade não pode ser tomada per se, pois sempre se dirige a alguém. Ela se dirige tanto ao próprio grupo mobilizado quanto a outros grupos, o que equivale dizer que se dirige a públicos. Esse fato a torna condicionada, portanto, pelos aspectos que definem esses agrupamentos como públicos e, de início, pelo que se presume sejam seus interesses comuns. E que aspectos seriam? Para desenvolvimento de nosso raciocínio, recorreremos aqui a alguns elementos proeminentes: afetação, controvérsia, virtualidade e performance.

No entender de Dewey (1927), as consequências de atos humanos sobre outras pessoas distintas das imediatamente implicadas ultrapassam os limites do âmbito privado das transações. Assim, o público se compõe de todos aqueles que se veem afetados pelas consequências indiretas das transações privadas e do reconhecimento dessas consequências nasce um interesse comum dessas outras pessoas e grupos. Na base de constituição de uma causa social, qualquer agrupamento que de alguma forma perceba um problema comum que o afete pode iniciar um processo mobilizador, sendo, ele próprio, nesse sentido, um público. Uma vez formado, pelo reconhecimento de uma afetação ou implicação comum num problema, esse público também se envolverá em uma controvérsia sobre as causas, as consequências e as circunstâncias do problema. Como definiu Blumer (1987), um público é um grupo de pessoas não apenas envolvidas numa questão, mas marcado também pela opinião e pela discussão. $\mathrm{O}$ posicionamento

\footnotetext{
${ }^{4} \mathrm{Em}$ trabalho anterior discutimos em maior detalhe sobre a visibilidade no processo de constituição de uma causa social (HENRIQUES, 2010).
} 
na controvérsia depende, portanto, do compartilhamento de opiniões e da formação de uma opinião coletiva.

Observemos que a afetação e a controvérsia podem irromper a qualquer momento. $\mathrm{O}$ fato de nos sentirmos afetados pelas consequências de atos privados de outrem pode ser deflagrado de diversas formas, quer pela nossa própria experiência ou contato com a experiência de outro com o qual nos identificamos, quer por tomarmos ciência de algum acontecimento que nos faz defrontar com o problema (pela mídia, por exemplo). Pode até mesmo ser desencadeado pela movimentação de quaisquer públicos que, uma vez afetados, propõem a questão e buscam fazer que nos reconheçamos como também submetidos às suas consequências, de modo mais próximo ou mais distante ${ }^{5}$. Postas em circulação, especialmente no ambiente midiático de visibilidade, tais questões compõem o conjunto de controvérsias que conformam uma agenda e se oferecem publicamente à discussão. É a possibilidade de atualização permanente das nossas percepções (individuais ou coletivas) e das controvérsias que desenha os públicos como extremamente dinâmicos, um permanente vir a ser.

A virtualidade é um aspecto importante tanto da formação dos públicos, como agrupamentos dinâmicos, quanto do interesse público, o que não diminui em nada a força desses processos. Antes, é ela que permite endereçar uma causa tanto a outros públicos quanto a interesses apenas presumidos. A proposição de uma causa deve pressupor a existência de um interesse público, remetendo à ideia de uma vontade geral e de um bem comum; uma vez postulada como sendo de interesse público, aqueles que a defendem precisarão esforçar-se todo o tempo para posicioná-la como sendo, de fato, algo que potencialmente interessa a todos. Tomamos isso como "um desafio que pressupõe permanente envolvimento nos dilemas morais e nas controvérsias que cercam o problema e, ainda, nas formas de concebê-lo e propô-lo ao conjunto da sociedade" (HENRIQUES, 2010, p. 95). Esse raciocínio tem uma importante consequência prática para os processos de mobilização social: uma causa social nunca se constitui integralmente, cumprindo de uma só vez todo o seu potencial. Ela resguarda um espaço

\footnotetext{
${ }^{5}$ Importante destacar aqui que há também a possibilidade de que alguém, reunindo os meios necessários para tal, intencionalmente simule essa movimentação, buscando infundir nos públicos um sentido de mobilização. As técnicas de propaganda apelam, com frequência, a recursos deste tipo, como se pode ver, por exemplo, em DOMENACH (1955) e em BERNAYS (2005).
} 
de virtualidade e requer constantes revisões no curso de sua existência, conforme o jogo comunicativo se desenrola.

No entanto, a efetivação de certo agrupamento como um público dependerá ainda da sua operação sob condições de publicidade, ou seja, da sua capacidade de expressar publicamente os seus interesses. Isso não significa simplesmente que os membros do público tenham capacidade e oportunidade de dar a ver suas opiniões individuais sobre a questão na qual se sentem envolvidos. Mais do que isso, tende a procurar também meios de expressar-se coletivamente, reforçar as suas capacidades e conquistar novas oportunidades para essa expressão e, além disso, tentar obter a adesão de outros públicos para a causa. É dessa forma que o grupo passa a ser reconhecido, de fato, como um público. Os públicos assim formados ganham, então, um movimento, que deve ser em algum momento e de algum modo perceptível. Daí uma dimensão performativa, gerada pela intensa circulação reflexiva de discursos (WARNER, 2002) e pelas formas que os públicos constroem com a finalidade de darem a ver sua própria movimentação (para si e para os outros). Tilly, Tarrow e McAdam (2009, p. 35) observam a necessidade de os movimentos que dirigem suas reivindicações às autoridades alcançarem essa expressão pública, através de "demonstrações de que a população é merecedora, unificada, numerosa e comprometida", ressaltando a ideia de mobilização social como performance que os movimentos apresentam no intuito de marcar suas demandas e criar e manter seus adeptos.

Esta é, propriamente, a dimensão mais ativa dos públicos ou, pelo menos, a que dá materialidade ao conjunto de percepções e de opiniões e ao coletivo que de algum modo as compartilham. Evidentemente, o fato de um público em certo momento não alcançar alguma expressão não lhe retira sua condição de público, dada a sua virtualidade. Mesmo em estado de latência (o que, no modelo bipolar de Melucci, já mencionado, significa estar fora da esfera de visibilidade) outros públicos podem virtualmente endereçar-lhe as suas questões, presumindo seus interesses - mesmo que contrários.

De tal maneira, tanto a formação como a movimentação de públicos dá-se por meio de intensas e constantes trocas comunicativas, no sentido de que os sujeitos necessitam pôr em comum suas percepções, opiniões, preferências, valores, crenças, conhecimentos e interesses e também por meio da geração de vínculos entre os sujeitos 
que resultam do defrontamento e do esforço despendido em compartilhar e gerar algo em comum. A própria dinâmica dessas trocas promove uma ininterrupta atualização do processo de formação do interesse público assim constituído ${ }^{6}$. Isso chama a atenção para o processo de geração de uma causa social como um processo interativo aberto e complexo, que mantém com o processo mobilizador uma relação de reflexividade. Queremos dizer com isso que a mobilização social ocorre em função de uma causa, mas, ao mesmo tempo, a própria afirmação pública de uma causa não pode prescindir de um processo de movimentação dos públicos em torno dela. Isso posto, é inapropriado considerar uma precedência da causa sobre a mobilização, como também o contrário. Essa forma de ver só pode ser sustentada precisamente se tomamos como princípio a condição pública e, portanto, a natureza comunicacional dos processos mobilizadores. De forma análoga, podemos postular que não há como dissociar a formação dos públicos da formação do interesse público, ou seja, a formação de um público não parte exatamente de um interesse geral previamente determinado, mas resulta, a cada momento, de reformulação e atualização que provêm do seu próprio movimento e de suas interações, ou seja, da comunicação que mantém.

A condição pública, enfim, não deriva simplesmente da visibilidade conferida a uma causa. Ela depende também da formação e da movimentação de públicos que possam publicamente sustentá-1a ${ }^{7}$, sob condições contingentes e mutáveis, o que evidencia o mútuo condicionamento desses fatores.

\section{A comunicação na ge ração cotidiana da condição pública}

A mobilização social corresponde, assim, a uma movimentação estratégica dos públicos com o intuito de não apenas se posicionarem (como públicos), mas também de conquistarem engajamento de outras pessoas, fazerem alianças com outros públicos e tentarem obter maior potência. Parece-nos evidente que a potência almejada depende de muitos fatores que vão além de uma boa e farta difusão da causa, tais como a força e a qualidade dos vínculos entre os sujeitos (os membros do público) e destes com a causa

\footnotetext{
${ }^{6}$ Em outro trabalho já observamos a instabilidade desse interesse público e o caráter provisório dos entendimentos coletivos (HENRIQUES, 2010).

${ }^{7}$ Referimo-nos aqui a uma capacidade de afirmação da causa no espaço público em termos de aceitabilidade e legitimidade.
} 
que defendem. Não é demais dizer que um grupo mobilizado luta constantemente contra a sua própria instabilidade e contra a instabilidade de sua causa.

Tomando sob essa perspectiva, vemos que a condição pública dos processos de mobilização social necessita ser cotidianamente gerada. Sem abdicar dos fenômenos extraordinários de ação em massa, cuja emergência episódica sempre é uma possibilidade, em sociedades democráticas complexas a vida dos públicos constitui uma dimensão importante, associada às interações na vida ordinária. A conceituação mais trivial da mobilização social traz, nesse sentido, um desafio para compreender os fenômenos associados a essa dimensão mais microscópica da vida social e também da ação política. Observar a formação e a movimentação dos públicos alcança ainda maior importância para a democracia, pela necessidade de resguardar as prerrogativas dos cidadãos de livre engajamento e participação na administração de questões públicas, ou seja, para que possam, na dimensão coletiva, existir, de fato, como públicos.

\section{REFERÊNCIAS:}

BERNAYS, Edward. Propaganda. New York: Ig Publishing, 2005.

BLUMER, Herbert. A massa, o público e a opinião pública. In: COHN, Gabriel (Org.). Comunicação e indústria cultural. 5. ed. São Paulo: T.A. Queiroz Editor, 1987. p. $177-186$.

DEWEY, Jonh. The Public and its problems. New York, H. Holt and Company, 1927.

DOMENACH, Jean-Marie. A propaganda política. São Paulo: Difel, 1955.

HARDT, Michael; NEGRI, Antônio. Multidão: guerra e democracia na era do império. Rio de Janeiro: Record, 2005.

HENRIQUES, Márcio S. (Org.). Comunicação e estratégias de mobilização social. 2.ed. Belo Horizonte: Autêntica, 2004.

- Ativismo, movimentos sociais e relações públicas. In: KUNSCH, Margarida; KUNSCH, Waldemar (Orgs.). Relações públicas comunitárias. A comunicação em uma perspectiva dialógica e transformadora. São Paulo: Summus, 2007. p. 92-104. 
LACLAU, Ernesto. New social movements and the plurality of the social. In: SLATER, David (Org.). New social move ments and the state in Latin America. Amsterdan: CEDLA, 1985. p. 27-42.

McADAM, D.; TARROW, S.; TILLY, C.; Para mapear o confronto político. Lua Nova, São Paulo, n. 76, p. 11-48, 2009.

MELUCCI, Alberto. Um objetivo para os movimentos sociais? Lua Nova, São Paulo, n. 17, p. 49-66, jun. 1989.

Challenging Codes: Collective action in the information age. Cambridge: Cambridge University Press. 1996.

TARROW, Sidney G. Power in Movement: Social Movements and Contentious Politics. 3. ed. New York: Cambridge University Press, 2011.

TILLY, Charles. From mobilization to revolution. New York: Ramdom House, 1978. Social Movements and (All Sorts of) Other Political Interactions Local, National, and International - Including Identities. Theory and Society, v. 27, n. 4, p. 453-480, 1998.

TORO, Jose Bernardo. Mobilização social: uma teoria para a universalização da cidadania. In: Comunicação e Mobilização Social. Brasília: UnB, 1996. p. 26-40.

TORO, Jose Bernardo; WERNECK, Nísia M. D. Mobilização social: um modo de construir a democracia e a participação. Belo Horizonte: Autêntica, 2004.

WARNER, Michael. Publics and Counterpublics. Public Culture, v. 14, n. 1, p. 49-90, 2002. 